\title{
The comparison of serum TGF-beta levels and associated polymorphisms in patients with coronary artery ectasia and normal coronary artery
}

Özgür Selim Ser ${ }^{1 *} \mathbb{D}$, Gökhan Çetinkal ${ }^{2}$, Onur Kiliçarslan ${ }^{1}$, Yalçın Dalgıç ${ }^{1}$, Servet Batit ${ }^{1}$, Kudret Keskin², Gulçin Özkara ${ }^{3}$, Ezgi Irmak Aslan³, Hülya Yilmaz Aydoğan ${ }^{3}$, Ahmet Yıldız and Zerrin Yiğit ${ }^{1}$

\begin{abstract}
Background: Coronary artery ectasia (CAE) is described as the enlargement of a coronary artery segment by 1.5 times or more, which is generally associated with the atherosclerotic process. Atherosclerotic changes lead to arterial remodeling result in CAE. In our study, we measured serum transforming growth factor (TGF)- $\beta 1$ levels, which have a protective role against atherosclerosis. Further, we aimed to assess the TGF- $\beta 1$ gene variants rs1800469 (-509C>T, C.-1347C > T) and rs1800470 (c.+29T>C, p.Pro10Leu, rs1982073), which might have an effect on TGF production. Overall, 2877 patients were screened including 56 patients with CAE and 44 patients with normal coronary arteries who were included in the study. Serum TGF- $\beta 1$ levels were measured using ELISA and compared between two groups. Additionally, TGF- $\beta 1$ rs1800469 and rs1800470 gene variations were determined using TaqMan ${ }^{\oplus}$ SNP Genotyping Assays.

Results: Serum TGF- $\beta 1$ levels were significantly lower in patients with CAE than in controls ( $p=0.012)$. However, there was no difference in terms of the genotype and allele distributions of TGF- $\beta 1$ rs 1800469 and rs 1800470 polymorphisms. Serum TGF- $\beta 1$ levels were higher in individuals carrying the TGF- $\beta 1$ rs 1800470 G allele (GG+AG) than in individuals with normal homozygous AA genotype in the CAE group ( $p=0.012$ ).

Conclusion: Our findings suggest that lower serum TGF- $\beta 1$ levels are associated with an increased risk for CAE development and that TGF- $\beta 1$ polymorphisms exert a protective effect. Furthermore, TGF- $\beta 1$ rs $1800470 \mathrm{G}$ allele carriers were shown to have higher TGF- $\beta 1$ levels in the CAE group. This suggests that having the $G$ allele in the TGF- $\beta 1$ rs 1800470 polymorphism could prevent CAE development.
\end{abstract}

Keywords: TGF- $\beta 1$, Polymorphism, Coronary artery ectasia

\section{Background}

Coronary artery ectasia (CAE) is described as the enlargement of an artery segment by 1.5 times or more compared with the adjacent normal segment. It is diagnosed angiographically, and it may be localized or diffused and observed in multiple branches. CEA, which is

\footnotetext{
* Correspondence: ozgurselimser@yahoo.com

'Department of Cardiology, Institute of Cardiology, Istanbul

University-Cerrahpasa, Haseki / Fatih, 34100 Istanbul, Turkey

Full list of author information is available at the end of the article
}

usually accompanied by coronary artery disease, can be congenital or acquired. Its frequency is reported to be around 1.4 to $5.3 \%$ based on studies that were conducted in Europe and the USA [1-4]. Both atherosclerosis and CAE share common risk factors such as male gender, hypertension, hyperlipidemia, smoking, and history of stroke $[2,5]$.

Pathophysiological findings change according to the underlying etiology in CAE patients. The etiology in half of the CAE patients is atherosclerosis. Atherosclerotic

\section{Springer Open}

() The Author(s). 2021 Open Access This article is licensed under a Creative Commons Attribution 4.0 International License, which permits use, sharing, adaptation, distribution and reproduction in any medium or format, as long as you give appropriate credit to the original author(s) and the source, provide a link to the Creative Commons licence, and indicate if changes were made. The images or other third party material in this article are included in the article's Creative Commons licence, unless indicated otherwise in a credit line to the material. If material is not included in the article's Creative Commons licence and your intended use is not permitted by statutory regulation or exceeds the permitted use, you will need to obtain permission directly from the copyright holder. To view a copy of this licence, visit http://creativecommons.org/licenses/by/4.0/. 
changes that occur in the tunica intima deteriorate the elastic composition of tunica media and lead to arterial remodeling, which results in $\mathrm{CAE}[4,5]$.

The transforming growth factor (TGF)- $\beta$ superfamily, which comprises TGF- $\beta$, activin, inhibin, growth and differentiation factors, and bone morphogenetic proteins, is a multifunction regulator that stimulates cell division, differentiation, organization, migration, and adhesion. TGF- $\beta$ has the following three isotypes: TGF- $\beta 1$, TGF$\beta 2$, and TGF- $\beta 3$. TGF- $\beta 1$ is the main effective isotype on the cardiovascular system $[6,7]$.

TGF- $\beta 1$ plays a key role in the pathogenesis of many cardiac diseases such as hypertension, in-stent restenosis, atherosclerosis, left ventricular hypertrophy, and heart failure. TGF- $\beta 1$ has a pleiotropic effect on cardiovascular cells $[6,8]$. It has been confirmed to be a protective cytokine because it is involved in maintaining vessel wall integrity, reducing inflammation, and maintaining the extracellular matrix (ECM) content in atherosclerosis. If the protective effect of TGF- $\beta 1$ is lost, the atherosclerosis process may accelerate. TGF- $\beta$ also contributes to plaque stabilization by increasing collagen production $[6,8,9]$.

Genetic polymorphism is the occurrence of two or more alleles of a gene in the region (locus) at a certain frequency in the same population. Polymorphisms are formed as a result of mutation. The most common type of genetic polymorphism among humans is single nucleotide polymorphisms, which are often called SNPs. Each SNP is an alteration of the DNA sequence of a nucleotide. Genetic polymorphism may also occur as a result of the addition or removal of DNA sequence of a nucleotide. Most polymorphisms are silent and do not alter gene function or expression, but a polymorphic variant of a gene may lead to abnormal expression or production of an abnormal form of the protein; this alteration can cause or be related to diseases.

Rs1800469 (T-509C) is a variation in the promoter region of the TGF- $\beta 1$ gene that affects gene transcriptional activity and serum TGF- $\beta 1$ levels. Rs1800470 (Leu10Pro) is a missense polymorphism that is located in the coding sequence of the TGF- $\beta 1$ gene and leads to alterations in the amino acid sequence and TGF- $\beta 1$ secretion from cells [10]. Both polymorphisms were found to be associated with coronary heart disease (CHD) complications in a large-scale meta-analysis study [11].

CAE is an inflammatory disease that develops in the background of atherosclerosis due to progressive destruction of collagen/elastin, and TGF- $\beta 1$ plays a prominent role in inflammatory processes. While TGF- $\beta 1$ variations and plasma levels have been investigated alone or together in different diseases, to the best of our knowledge, there has been no investigation regarding the effect of TGF- $\beta 1$ variations on TGF- $\beta 1$ levels in CAE disease. Moreover, in other populations, TGF- $\beta 1$ variations have not been examined enough except in thoracic and abdominal aortic aneurysm studies. Based on the hypothesis that TGF- $\beta 1$ is a protective cytokine against atherosclerosis and that variations in the TGF- $\beta 1$ gene affect the pathogenesis of CAE, we determined the effects of TGF- $\beta 1$ rs1800469 and rs1800470 polymorphisms in the development of CAE.

\section{Methods}

\section{Study population}

In this prospective observational study, 2877 patients who underwent elective coronary angiography from January 2017 through December 2017 were evaluated, and among them, 56 patients with CAE were included in the study. The control group comprised 44 patients who were referred for CAG either due to a positive exercise test or typical ischemic symptoms and found to be free of coronary artery disease (normal coronary arteries). Exclusion criteria were serious previous psychiatric disorders, $\geq 50 \%$ occlusive coronary artery lesion with CAE, acute coronary syndromes, serious pulmonary hypertension, extremely high blood pressure $(>180 / 110 \mathrm{mmHg})$ despite antihypertensive treatment, liver disease, history of stroke, myocardial infarction, previous cardiac surgery, collagenous disease, chronic renal disease, peripheral artery disease, or hyperthyroidism.

When we recruited the patients, in order to avoid the selection bias, we enrolled the first patient with normal coronary arteries, who was admitted after a patient with CAE, as the control.

Ethics board approval was obtained from the Clinical Research Ethics Committee and written, and informed consent was obtained from each participant. Those who were unable to cooperate or who did not comply with the study requirements were excluded from the study.

\section{Genotyping}

Blood samples were collected into EDTA containing tubes and total DNA was isolated according to the protocol of a commercial kit (PureLink Genomic DNA Mini Kit, Cat. No: K182002, Thermo Fisher Scientific, USA). DNA concentration and purity were determined using a NanoDrop 2000 Spectrophotometer (Thermo Fisher Scientific). TGF- $\beta 1$ rs1800469 [-509 G>A (C>T)] (Assay ID: C_8708473_10) and rs $1800470 \quad[+869 \mathrm{~A}>\mathrm{G}$ $(\mathrm{T}>\mathrm{C})$ ] (Assay ID: C_22272997_10) variations were detected by real-time PCR using ready-to-use TaqMan ${ }^{\circ}$ SNP Genotyping Assays (40X) (Cat. No: 4351379, Thermo Fisher Scientific) in which one allele was labeled with $\mathrm{FAM}^{\mathrm{TM}}$ and the other was labeled with $\mathrm{VIC}^{\circ}$ fluorescent dyes. The PCR reaction mix was prepared according to TaqMan ${ }^{\circ}$ Universal Master Mix II (UNG) (Cat. No: 4440038, Thermo Fisher Scientific) protocol and the 
Applied Biosystems 7500 Real-Time PCR Instrument (Thermo Fisher Scientific) was used for thermal cycling with the following conditions: $2 \mathrm{~min}$ at $50^{\circ} \mathrm{C}$ (pre-incubation), $2 \mathrm{~min}$ at $95^{\circ} \mathrm{C}$ (activation), $15 \mathrm{~s}$ at $95^{\circ} \mathrm{C}$ (denaturation), and $1 \mathrm{~min}$ at $60^{\circ} \mathrm{C}$ (binding/extension/ reading) (40 cycles). Genotypes were automatically determined by the instrument in accordance with the FAM or VIC fluorescence signal produced during allele amplification.

\section{Detection of serum TGF- $\beta 1$ levels}

Blood samples were collected into plain tubes from participants who had fasted overnight and serum samples were obtained via centrifuged blood samples at room temperature for $10 \mathrm{~min}$ at $1500 \times \mathrm{g}$. Serum samples were immediately frozen at $-80^{\circ} \mathrm{C}$ until the ELISA test was performed. Human TGF beta 1 Platinum ELISA (Cat. No: BMS249/4, Thermo Fisher Scientific), which is a commercial kit, was used to determine the TGF- $\beta 1$ levels in serum samples according to the test protocol. Absorbance (OD) measurements were performed using an ELISA plate reader (Multiskan ${ }^{\mathrm{TM}}$ GO Microplate Spectrophotometer) at a wavelength of $450 \mathrm{~nm}$. After automatically calculating the standard concentrations $(\mathrm{ng} / \mathrm{mL}$ for $T G F-\beta 1$ ), serum concentrations were detected using the linear regression equation according to the optical density (OD) values.

\section{Statistical analysis}

Statistical analyses were performed using SPSS 21 (SPSS Inc., Chicago, IL, USA). The data distribution was tested for normality using the Kolmogorov-Smirnov test. Allele frequencies were estimated by gene counting methods. Differences in the distribution of genotypes and alleles were assessed using the chi-square test. Mean values were compared between the patients and controls using an unpaired Student's $t$ test and an analysis of variance (ANOVA). The statistical significance limit was accepted as $p<0.05$. Diagnostic accuracy of TGF- $\beta 1$ was evaluated using the area under receiver operating characteristic (ROC) curve (AUC) along with its 95\% confidence interval (95\% CI).

\section{Results}

Demographic and clinical features of the study groups are shown in Table 1. Both groups had comparable mean ages. The ratio of male gender and the prevalence of hypertension and hyperlipidemia were higher in CAE patients than in controls. Biochemical and hematological parameters of the study groups are shown in Table 2. Hematocrit levels were higher and TGF- $\beta 1$ levels were lower in CAE patients than in controls.

Genotype and allele distributions of TGF- $\beta 1$ rs1800469 and rs1800470 are shown in Table 3. There were no statistically significant differences between the study groups. In addition, genotype and allele distributions of TGF- $\beta 1$ rs1800469 and rs1800470 did not deviate from the Hardy-Weinberg equation (HWE) in CAE patients and healthy controls.

The association of TGF- $\beta 1$ rs1800469 (G>A) genotypes with clinical and biochemical features is shown in Table 4. We did not observe any statistically significant association when comparing the effects of TGF- $\beta 1$ rs1800469 genotypes on biochemical parameters in study groups. However, patients with the TGF- $\beta 1$ rs1800469 homozygous normal GG genotype were more likely to have decreased TGF- $\beta 1$ level in the CAE group. This association showed the effect of TGF- $\beta 1$ rs1800469 on serum TGF- $\beta 1$ levels as ascending levels in the following order: GG < GA < AA. However, this tendency was not observed in controls.

The association of TGF- $\beta 1$ rs1800470 (A>G) genotypes with clinical and biochemical features is shown in Table 5. Serum levels of TGF- $\beta 1$ were observed to be lower in CAE patients with the common AA genotype than in heterozygous AG carriers $(p=0.030)$. Additionally, CAE patients with the rare $G$ allele had higher TGF- $\beta 1$ levels than those with AA genotype $(p=0.012)$. We also observed that the blood platelet count was higher in CAE patients with the common A allele (AA+

Table 1 Demographic and clinical features of study groups

\begin{tabular}{|c|c|c|c|}
\hline & \multicolumn{2}{|l|}{ Study groups } & \multirow{2}{*}{$\begin{array}{l}p \\
\text { value }\end{array}$} \\
\hline & CAE patients $(n=56)$ & Control patients $(n=44)$ & \\
\hline Age (year) & $62.23 \pm 1.284$ & $59.95 \pm 1.79$ & 0.292 \\
\hline Gender (F/M) & $16 / 40$ & $26 / 18$ & 0.002 \\
\hline EF (\%) & $57.02 \pm 1.07$ & $58.55 \pm 0.88$ & 0.292 \\
\hline HT (\%) & $38(67.9)$ & $21(47.7)$ & 0.042 \\
\hline DM (\%) & $22(39.3)$ & $11(25)$ & 0.132 \\
\hline Hyperlipidemia (\%) & $33(58.9)$ & $13(29.5)$ & 0.003 \\
\hline
\end{tabular}

Values were derived by using an independent-sample $t$ test. The results were shown as mean \pm SD and $\%$. Values of $p<0.05$ were considered statistically significant

CAE coronary artery ectasia, DM diabetes mellitus, HT hypertension, EF ejection fraction 
Table 2 Biochemical and hematological parameters of study groups

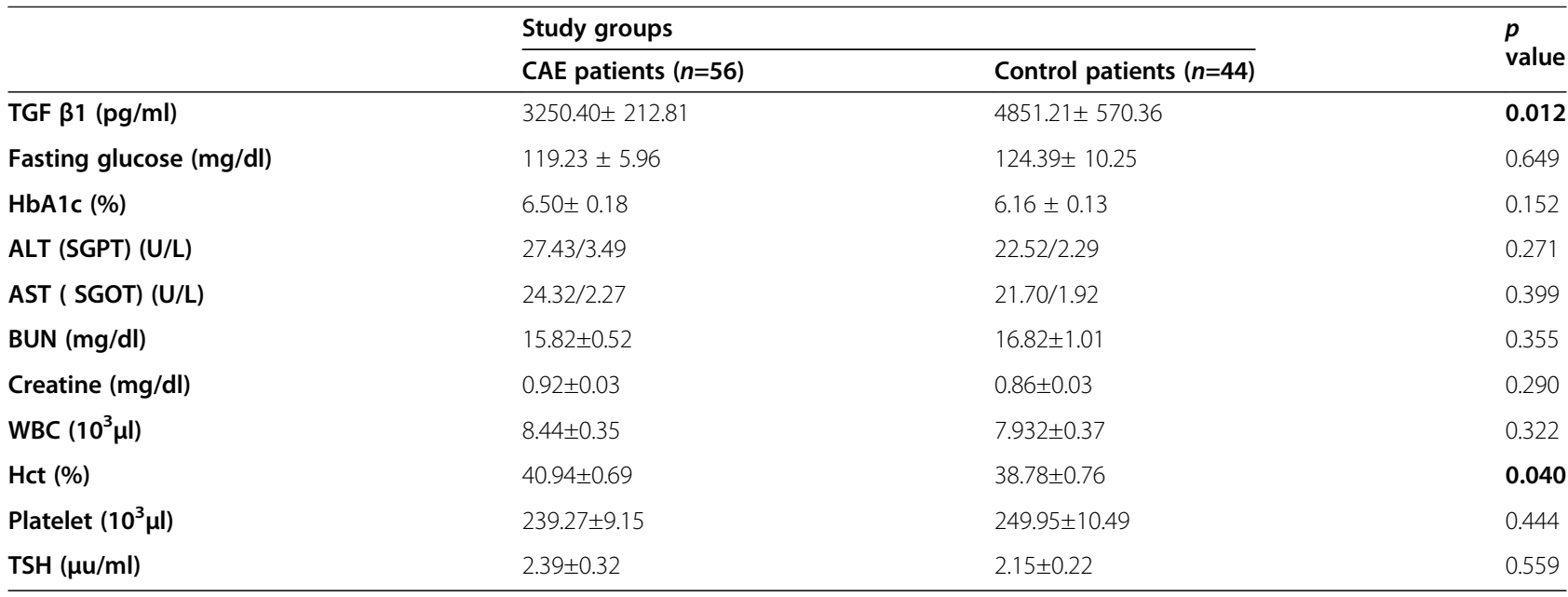

Values were derived by using an independent-sample $t$ test. The results were shown as mean \pm SD and \%. Bold values of $p<0.05$ were considered statistically significant

CAE coronary artery ectasia, TGF $\beta 1$ transforming growth factor beta 1, HgA1c hemoglobin A1c, BUN blood urea nitrogen, $H g b$ hemoglobin, WBC white blood cell, $\mathrm{Hct}$ hematocrit, TSH thyroid stimulating hormone

AG) than in patients with the GG genotype $(p=0.018)$. Serum aspartate aminotransferase (AST) levels were significantly lower in A allele carriers (AA+AG) in controls than in individuals with the GG genotype $(p=0.019)$.

ROC analysis of the diagnostic accuracy of TGF- $\beta 1$ in CAE patients is shown in Fig. 1. The AUC value of serum TGF- $\beta 1$ levels for predicting CAE was $0.64(95 \%$ CI 0.53-0.78 $p=0.01)$. TGF- $\beta 1$ blood level $<3980 \mathrm{mcg} / \mathrm{dL}$

Table 3 TGF $\beta 1$ genotype and allele distributions of CAE and control patients

\begin{tabular}{ccl}
\hline Genotype and allele distributions & CAE ( $\boldsymbol{n = 5 6 )}$ & Control ( $\boldsymbol{n = 4 4 )}$ \\
\hline \multicolumn{3}{c}{ TGF $\boldsymbol{\beta}$ 1rs1800469 genotypes (\%) } \\
GG & $19(33.9 \%)$ & $16(36.4 \%)$ \\
AA & $12(21.4 \%)$ & $8(18.2 \%)$ \\
GA & $25(44.6 \%)$ & $20(45.5 \%)$ \\
rs1800469 Alleles (\%) & $63(56.25 \%)$ & $52(59.09 \%)$ \\
G & $49(43.75 \%)$ & $36(40.91 \%)$ \\
A & $p=0.486$ & $p=0.691$ \\
HWE & TGF $\beta$ 1rs1800470Genotypes (\%) \\
AA & $23(41.1 \%)$ & $13(29.5 \%)$ \\
GG & $10(17.9 \%)$ & $8(18.2 \%)$ \\
AG & $23(41.1 \%)$ & $23(52.3 \%)$ \\
rs1800470 Alleles (\%) & & \\
A & $69(61.61 \%)$ & $49(55.68 \%)$ \\
G & $43(38.39 \%)$ & $39(44.32 \%)$ \\
HWE & $p=0.324$ & $p=0.694$ \\
\hline
\end{tabular}

The values in the table are given in $n$ (\%) CAE coronary artery ectasia, TGF $\beta 1$ transforming growth factor beta1, HWE Hardy-Weinberg Equilibrium, $n$ sample number had $74 \%$ sensitivity and $61 \%$ specificity for predicting CAE.

\section{Discussion}

The incidence of CAE was rare, at approximately $2 \%$ in our cohort, and the incidence based on previous studies ranged from 1.4 to $5.3 \%$ that were conducted in Europe and the USA. Therefore, our findings are consistent with the literature [1-4].

To the best of our knowledge, the present study is the first to show the relationship of TGF- $\beta 1$ gene variations with the clinical/biochemical parameters and serum TGF- $\beta 1$ levels in patients with CAE. In the present study, serum TGF- $\beta 1$ levels were significantly lower in CAE patients than in controls and based on ROC analysis the discriminatory power seems to be moderate. Moreover, genotype distributions of TGF- $\beta 1$ rs 1800469 and rs 1800470 polymorphisms were not significantly different between the CAE and control groups. However, the common homozygous AA genotype of the TGF- $\beta 1$ rs1800470 polymorphism had lower serum TGF- $\beta 1$ levels than patients with the rare $\mathrm{G}$ allele carriers (GG+ AG genotypes) in the CAE group ( $p=0.012)$. In addition, we observed that the TGF- $\beta 1$ rs1800469 polymorphism was associated with serum TGF- $\beta 1$ levels, which were increased in CAE patients the following order: $G G<G A$ $<$ AA. However, the increases were not statistically significant. Lower TGF- $\beta 1$ blood levels may increase the risk of CAE development. Considering the low TGF- $\beta 1$ levels in the CAE group in this study, we believe that having the TGF- $\beta 1$ rs $1800470 \mathrm{G}$ allele (GG+AG genotypes) and TGF- $\beta 1$ rs1800469 A allele (AA+AG genotypes) may have a protective effect against the development of CAE. 


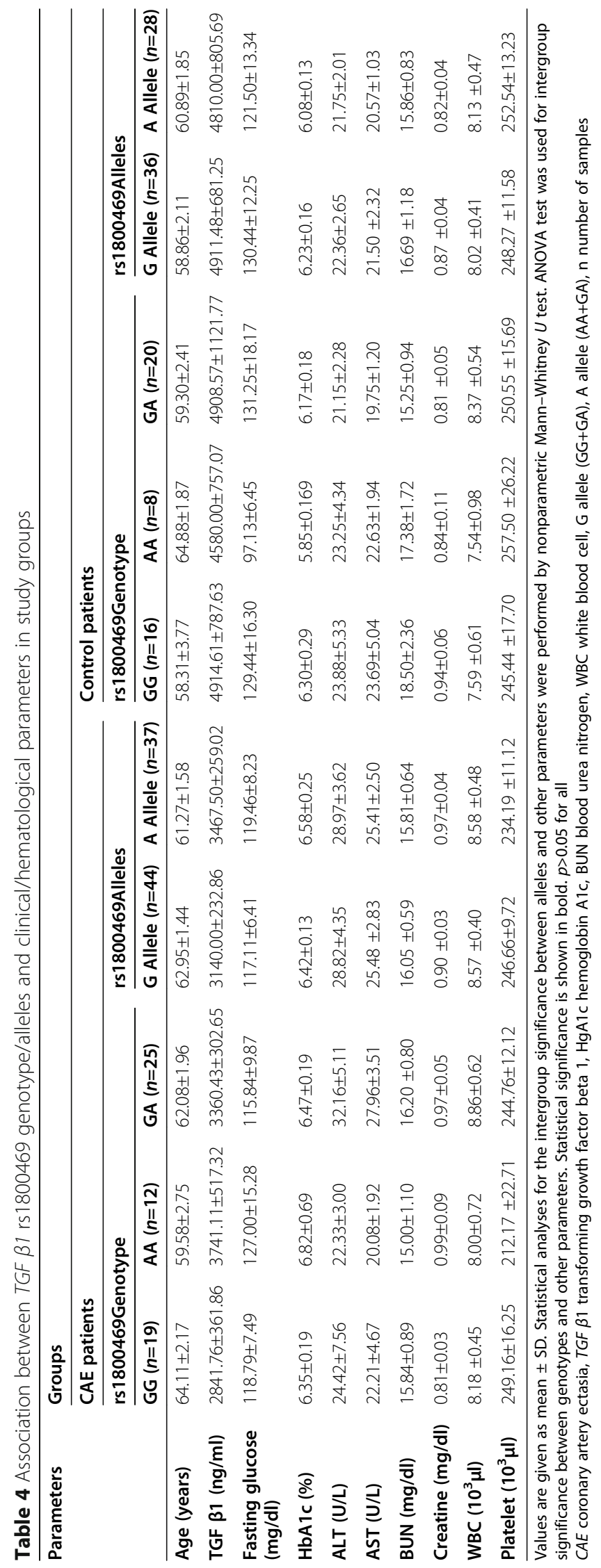




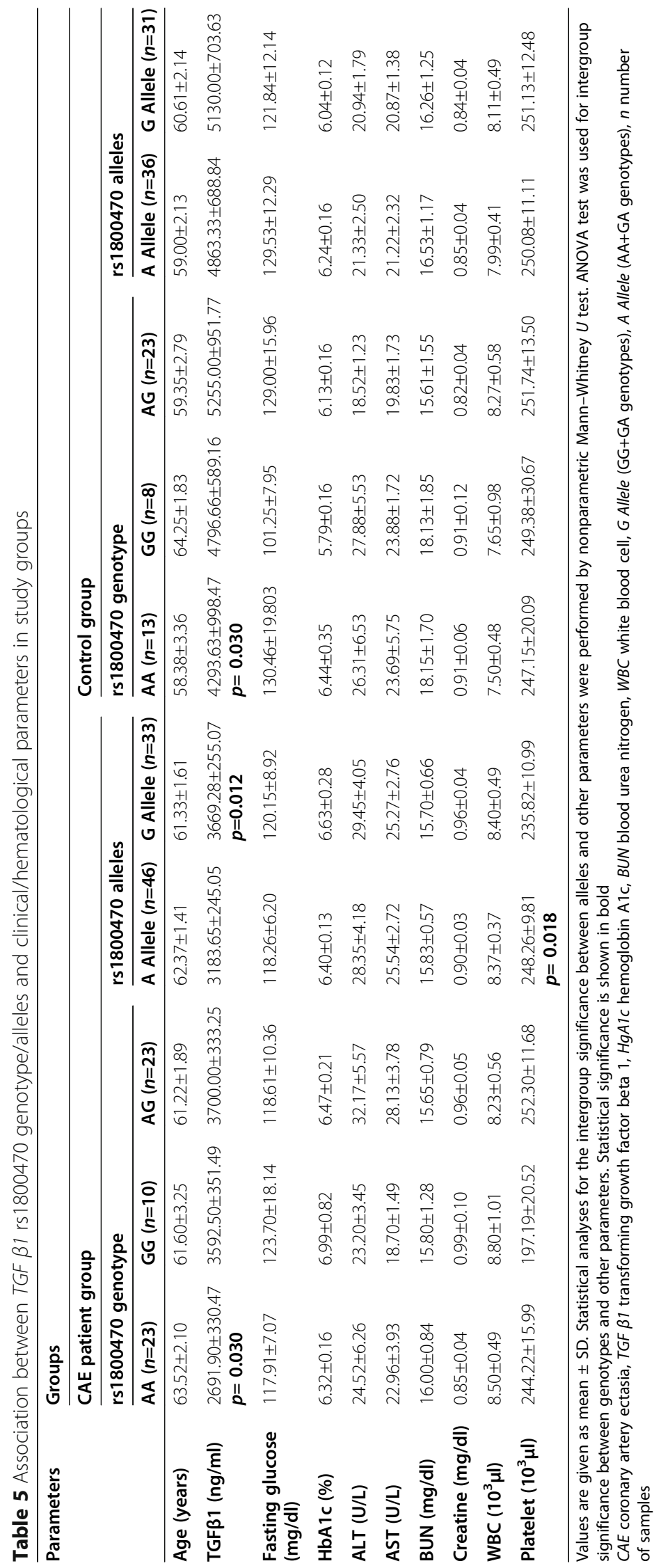




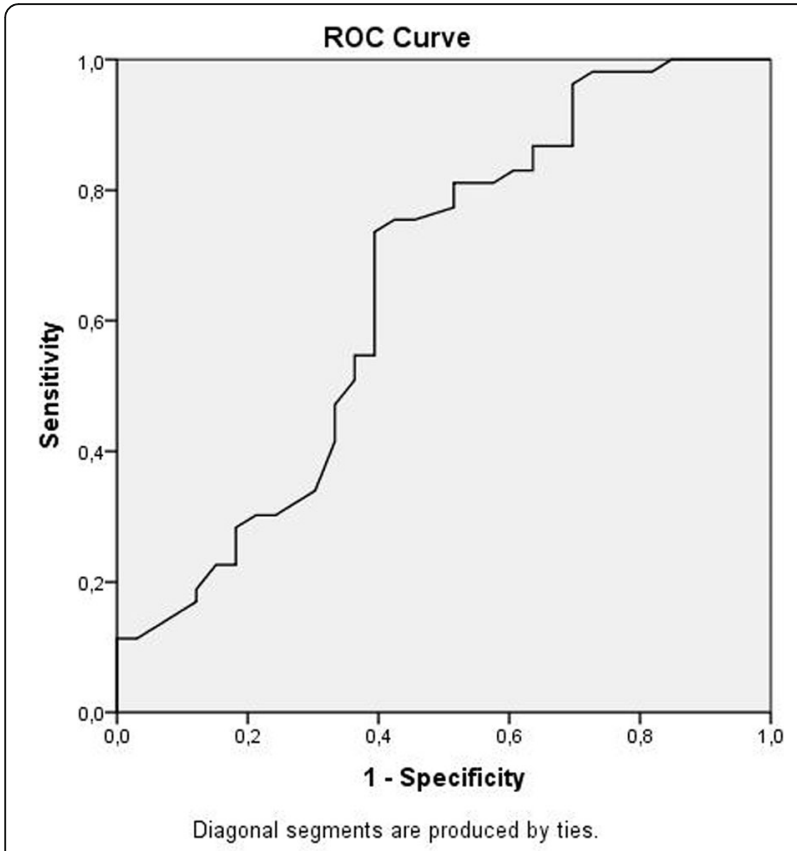

Fig. 1 Receiver operating characteristics curve analysis of TGF- $\beta 1$ levels to CAE

The main event in CAE pathogenesis is destruction of the ECM by arterial remodeling that is caused by serine proteinase, lysosomal proteinase, and metalloproteinases $[4,5,12]$. Because TGF- $\beta$ maintains vessel wall integrity, reduces inflammation, and maintains the ECM content in atherosclerosis, when any of its effects on endothelial cells are missing, the atherosclerosis process accelerates. The role of TGF- $\beta$ signaling in the pathogenesis of cardiovascular diseases has been reported previously $[6,8$, 9]. In these studies, an inverse relationship between serum TGF- $\beta 1$ levels and the development of atherosclerosis was demonstrated, and it was suggested that TGF- $\beta 1$ concentration is severely suppressed in advanced atherosclerosis $[8,9]$. In addition, Tashiro et al. demonstrated that the TGF- $\beta$ plasma concentration has a prognostic significance in patients with proven CAD. In this study, the low plasma concentration TGF- $\beta$ group had a poor prognosis of survival without cardiovascular events and survival without coronary interventions compared to the high plasma concentration TGF- $\beta$ group [13].

These results show that TGF- $\beta$ is a protective cytokine. Although there is no study examining the TGF- $\beta$ blood levels in patients with CAE in the literature, the low plasma TGF- $\beta$ concentrations that were found in CAE patients in our study may cause the increased risk of CAE development. In contrast to our findings, Yetkin et al. reported that plasma TGF- $\beta 1$ levels were significantly increased in patients with CAE and CAD compared to age- and sex-matched patients with CAD alone
[14]. In our study, the control group comprised individuals with normal coronary arteries. Therefore, the difference between the findings in the two studies could be attributed to different characteristics of the control group.

A few gene polymorphism studies on the atherosclerotic origin of CAE have been reported. These studies demonstrated the relationship between $\mathrm{CAE}$ and the c.894 G>T polymorphism in the endothelial nitric oxide synthase gene, HOGG1, Ser326Cys gene polymorphism, deletion in angiotensin I converting enzyme gene, and the HLA-DR B1, DR16, DQ2, and DQ5 genotypes [1518]. Furthermore, many studies have reported the effect of TGF- $\beta 1$ gene polymorphism on atherosclerotic cardiovascular or other cardiac diseases. In a significant part of these studies, TGF- $\beta 1$ rs1800469 and rs1800470 polymorphisms were associated with restenosis after a coronary stent and coronary artery disease $[19,20]$. Additionally, mutation of TGF- $\beta$ signal pathway components such as TGFBR1 and TGFBR2 is directly involved in the progression of the aortic aneurysm [21]. Zuo et al. indicated the increased risk of abdominal aortic aneurysm for individuals with the TGF- $\beta 1$ rs1800469 TT(AA) genotype compared with those with the $\mathrm{CC}(\mathrm{GG})$ genotype [22]. No studies have investigated the relationship between TGF- $\beta 1$ gene variations and CAE. In our study, we investigated the relationship between TGF- $\beta 1$ rs1800469 and rs1800470 polymorphisms and CAE. No significant relationship was found between TGF- $\beta 1$ polymorphisms at rs1800469 and rs1800470 and CAE. With these results, a single polymorphism alone may not be responsible for its etiology, especially considering the multidimensional presentation of the disease. Although several polymorphisms have been identified, the exact polymorphism that describes the etiology of CAE remains uncertain.

Rs1800470 is located within the TGF- $\beta 1$ gene exons, affecting the amino acid chance of developing Leu10Pro. Proline substitution at codon 10 may result from an altered intercellular signaling network or increased transcription. This may cause changes in the chemical properties and structure of the TGF- $\beta 1$ protein [11]. In CAD patients, the $\mathrm{T}(\mathrm{A})$ allele of TGF- $\beta 1$ rs 1800470 $(29 \mathrm{~T} / \mathrm{C})$ was reportedly associated with low serum TGF$\beta 1$ levels compared to homozygous CC(GG) [23]. These findings may demonstrate the anti-inflammatory effect of TGF- $\beta 1$ on the vessel wall. In addition, Fragoso et al. demonstrated the TGF- $\beta 1$ rs 1800470 (29T/C) polymorphism was related to restenosis after coronary stenting. It was also shown in the same study that individuals with the TT haplotype TGF- $\beta 1$ rs1800470 (29T/C) produced less TGF- $\beta 1$ [19]. Similar to these studies, we observed that serum TGF- $\beta 1$ levels may differ in patients with CAE according to the TGF- $\beta 1$ rs1800469 and 
rs1800470 polymorphisms. In the present study, homozygous AA genotype of the TGF- $\beta 1$ rs 1800470 polymorphism had lower serum TGF- $\beta 1$ levels than patients with the $G$ allele carriers (GG+AG genotypes) in the CAE group. This may lead to a decrease in the antiinflammatory effect and an acceleration in the development of CAE.

Rs1800469 is a single nucleotide polymorphism that is located within the promoter region of the TGF- $\beta 1$ gene. This mutation causes a change in the amount of TGF- $\beta 1$ that is produced without changing the protein structure. The $T$ allele of TGF- $\beta 1$ rs1800469 was shown to be associated with a higher serum TGF- $\beta 1$ level [24]. Cao et al. found that the $-509 \mathrm{~T}$ allele (TGF- $\beta 1$ rs 1800469 A allele) was associated with higher TGF- $\beta 1$ expression and more severe interstitial fibrosis. Based on their findings, they suggested that increased TGF- $\beta 1$ expression by the $-509 \mathrm{~T}$ allele may cause overproduction of extracellular matrix components, resulting in progressive atrial augmentation, fibrosis, and susceptibility to lone atrial fibrillation [25]. In the present study, we observed that the TGF- $\beta 1$ rs1800469 polymorphism was associated with serum TGF- $\beta 1$ levels, which were increased in the following order in CAE patients: GG < GA < AA. However, the increases were not statistically significant.

The CAE group in the present study comprised individuals who had CAE with atherosclerosis. Studies have revealed that CAE is a variant of atherosclerosis and has similar pathogenesis. In this situation, it would not be a surprise to have similar risk factors. In our study, the prevalence of hypertension, hyperlipidemia, and male sex were higher in patients with CAE than in controls. Similar to our findings, Gunes et al. found in their study that the prevalence of hypertension and hyperlipidemia, which are clinical features of CAE patients, was more frequent in CAE patients than in controls who had normal coronary arteries [26]. These are also well-known risk factors for the development of CAD. Moreover, Kamal et al. also found in their study that male gender was frequent in patients with $\mathrm{CAE}$ and an independent risk factor for CAE development [27].

\section{Limitations}

This was a single-center study with a relatively small number of patients. In addition, there was no long-term follow-up.

\section{Conclusion}

Thus, TGF- $\beta 1$ levels were significantly lower in CAE patients than in controls in our study. These results suggest that TGF- $\beta 1$ may have a protective effect against CAE development. Furthermore, TGF- $\beta 1$ rs1800470 G allele carriers were shown to have higher TGF- $\beta 1$ levels than patients with the AA genotype in the CAE group.
This suggests that having the $\mathrm{G}$ allele in the TGF- $\beta 1$ rs1800470 polymorphism could prevent CAE development. Considering the higher prevalence of hyperlipidemia and hypertension that is found in patients with CAE in our study, strict control of hyperlipidemia and hypertension may be a protective strategy against CAE development

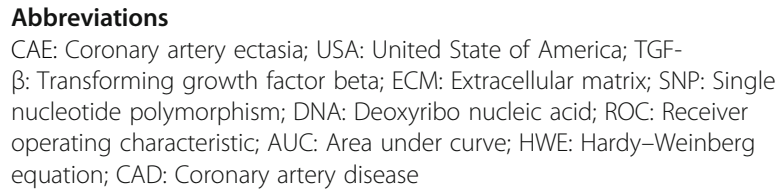

\section{Acknowledgements}

None

\section{Authors' contributions}

ÖSS: conceptualization, formal analysis, writing-original draft; GÇ: writing-original draft, writing - review and editing; OK: data curation, visualization; YD: data curation, visualization SB: data curation, visualization; KK: writing — review and editing; GÖ: data curation, investigation; ElA: data curation, investigation; HYA: writing-review and editing; AY: supervision; ZY: supervision. All authors have read and approved the manuscript.

\section{Funding}

This research did not receive any specific grant from funding agencies in the public, commercial, or not-for-profit sectors.

\section{Availability of data and materials}

All data generated or analyzed during this study are included in this published article.

\section{Declarations}

\section{Ethics approval and consent to participate}

Ethical board approval was obtained by the İstanbul Üniversity İstanbul Medical Faculty Clinical Research Ethics Committee (Ref No: 59075288-900-) and a written informed consent to participate was obtained from each participant.

\section{Consent for publication}

Not applicable

\section{Competing interests}

The authors declare that they have no competing interests.

\section{Author details}

${ }^{1}$ Department of Cardiology, Institute of Cardiology, Istanbul University-Cerrahpasa, Haseki / Fatih, 34100 Istanbul, Turkey. ${ }^{2}$ Department of Cardiology, Sisli Hamidiye Etfal Training and Research Hospital, Health Sciences University, Istanbul, Turkey. ${ }^{3}$ Department of Molecular Medicine, Aziz Sancar Institute of Experimental Medicine, Istanbul University, Istanbul, Turkey.

Received: 8 December 2020 Accepted: 16 March 2021

Published online: 31 March 2021

References

1. Hartnell GG, Parnell BM, Pridie RB (1985) Coronary artery ectasia. Its prevalence and Clinical significance in 4993 patients. Br Heart J 54(4):392395. https://doi.org/10.1136/hrt.54.4.392

2. Swaye PS, Fisher LD, Litwin P, Vignola PA, Judkins MP, Kemp HG, Mudd JG, Gosselin AJ (1983) Aneurysmal coronary artery disease. Circulation 67(1): 134-138. https://doi.org/10.1161/01.cir.67.1.134

3. Demopoulos VP, Olympios CD, Fakiolas CN, Pissimissis EG, Economides NM, Adamopoulou E, Foussas SG, Cokkinos DV (1997) The natural history of 
aneurysmal coronary artery disease. Heart 78(2):136-141. https://doi.org/1 $0.1136 /$ hrt.78.2.136

4. Antoniadis AP, Chatzizisis YS, Giannoglou GD (2008) Pathogenetic mechanisms of coronary ectasia. Int J Cardiol 130(3):335-343. https://doi. org/10.1016/j.jjcard.2008.05.071

5. Glagov S, Weisenberg E, Zarins CK, Stankunavicius R, Kolettis GJ (1987) Compensatory enlargement of human atherosclerotic coronary arteries. N Engl J Med 316(22):1371-1375. https://doi.org/10.1056/NEJM1987052 83162204

6. Ruiz-Ortega M, Rodríguez-Vita J (2007) TGF- $\beta$ signaling in vascular fibrosis. Cardiovasc Res 74(2):196-206. https://doi.org/10.1016/j.cardiores.2007.02.008

7. Moustakas A, Pardali K, Gaal A, Heldin CH (2002) Mechanisms of TGF- $\beta$ signaling in the regulation of cell growth and differentiation. Immunol Lett 82:85-91. https://doi.org/10.1016/s0165-2478(02)00023-8

8. Grainger DJ (2004) Transforming growth factor-b and atherosclerosis: so far, so good for the protective cytokine hypothesis. Arterioscler Thromb Vasc Biol 24(3):399-404. https://doi.org/10.1161/01.ATV.0000114567.76772.33

9. Borkowski P, Robinson MJ, Kusiak JW, Borkowski A, Brathwaite C, Mergner WJ (1995) Studies on TGF- $\beta 1$ gene expression in the intima of the human aorta in regions with a high and low probability of developing atherosclerotic lesions. Mod Pathol 8(5):478-482

10. Grainger DJ (2007) TGF-beta and atherosclerosis in man. Cardiovasc Res 74(2):213-222. https://doi.org/10.1016/j.cardiores.2007.02.022

11. Morris DR, Moxon JV, Biros E, Krishna SM, Golledge J (2012) Meta-analysis of the association between transforming growth factor-beta polymorphisms and complications of coronary heart disease. PLoS One 7(5):e37878. https:// doi.org/10.1371/journal.pone.0037878

12. Chatzizisis YS, Coskun AU, Jonas M, Edelman ER, Feldman CL, Stone PH (2007) Role of endothelial shear stress in the natural history of coronary atherosclerosis and vascular remodeling: molecular, cellular, and vascular behavior. J Am Coll Cardiol 49(25):2379-2393. https://doi.org/10.1016/j.jacc.2 007.02.059

13. Tashiro H, Shimokawa H, Sadamatu K, Yamamoto K (2002) Prognostic significance of plasma concentrations of transforming growth factor-beta in patients with coronary artery disease. Coron Artery Dis 13(3):139-143. https://doi.org/10.1097/00019501-200205000-00001

14. Yetkin E, Acikgoz N, Sivri N, Tekin GO, Yagmur J, Aksoy Y, Turhan H (2007) Increased plasma levels of cystatin $\mathrm{C}$ and transforming growth factor-beta1 in patients with coronary artery ectasia: can there be a potential interaction between cystatin $\mathrm{C}$ and transforming growth factor-beta1. Coron Artery Dis 18(3):211-214. https://doi.org/10.1097/MCA.0b013e328087bd98

15. Arif Yalcin A, Faruk Akturk I, Celik O, Erturk M, Sabri Hancer V, Yalcin B, Isiksacan N, Uzun F, Ozbey Ozyilmaz S, Biyik I (2014) Coronary artery ectasia is associated with the C.894G>T (Glu298Asp) polymorphism of the endothelial nitric oxide synthase gene. Tohoku J Exp Med 232(2):137-144. https://doi.org/10.1620/tjem.232.137

16. Hsu PC, Wang CL, Su HM, Juo SH, Lin TH, Voon WC, Shin SJ, Lai WT, Sheu SH (2014) The hOGG1 Ser326Cys gene polymorphism and the risk of coronary ectasia in the Chinese population. Int J Mol Sci 15(1):1671-1682. https://doi.org/10.3390/ijms15011671

17. Gulec S, Atmaca Y, Kilickap M, Akyürek O, Aras O, Oral D (2003) Angiographic assessment of myocardial perfusion in patients with Isolated coronary artery ectasia. Am J Cardiol 91:996-999. https://doi.org/10.1016/ s0002-9149(03)00123-1

18. Akdemir $R$, Ozhan $H$, Gunduz $H$, Erbilen E, Yazici M, Duran S, Orkunoglu F, Albayrak S, Imirzalioglu N, Uyan C (2004) HLA-DR B1 and DQ B1 polymorphisms in patients with coronary artery ectasia. Acta Cardiol 59(5): 499-502. https://doi.org/10.2143/AC.59.5.2005222

19. Fragoso JM, Zuñiga-Ramos J, Arellano-González M, Alvarez-León E, VillegasTorres BE, Cruz-Lagunas A, Delgadillo-Rodriguez H, Peña-Duque MA, Martínez-Ríos MA, Vargas-Alarcón G (2015) The T29C (rs1800470) polymorphism of the transforming growth factor- $\beta 1$ (TGF- $\beta 1$ ) gene is associated with restenosis after coronary stenting in Mexican patients. Exp Mol Pathol 98(1):13-17. https://doi.org/10.1016/j.yexmp.2014.11.007

20. Osadnik T, Strzelczyk JK, Reguła R, Bujak K, Fronczek M, Gonera M, Gawlita M, Wasilewski J, Lekston A, Kurek A, Gierlotka M, Trzeciak P, Hawranek M, Ostrowska Z, Wiczkowski A, Poloński L, Gąsior M (2016 Mar 1) The relationships between polymorphisms in genes encoding the growth factors TGF- $\beta 1$, PDGFB, EGF, bFGF and VEGF-A and the restenosis process in patients with stable coronary artery disease treated with bare metal stent. PLoS One 11(3):e0150500. https://doi.org/10.1371/journal.pone.0150500
21. Loeys BL, Schwarze U, Holm T, Callewaert BL, Thomas GH, Pannu H, De Backer JF, Oswald GL, Symoens S, Manouvrier S, Roberts AE, Faravelli F, Greco MA, Pyeritz RE, Milewicz DM, Coucke PJ, Cameron DE, Braverman AC, Byers PH, De Paepe AM, Dietz HC (2006) Aneurysm syndromes caused by mutations in the TGF-beta receptor. N Engl J Med 355(8):788-798. https:// doi.org/10.1056/NEJMoa055695

22. Zuo S, Xiong J, Wei Y, Chen D, Chen F, Liu K, Wu T, Hu Y, Guo W (2015) Potential interactions between genetic polymorphisms of the transforming growth factor- $\beta$ pathway and environmental factors in abdominal aortic aneurysms. Eur J Vasc Endovasc Surg 50(1):71-77. https://doi.org/10.1016/j. ejvs.2015.04.010

23. Yang M, Zhu M, Tang L, Zhu H, Lu Y, Xu B (2016 Aug) Polymorphisms of TGF $\beta-1$ and TGFBR2 in relation to coronary artery disease in a Chinese population. Clin Biochem 49(12):873-878. https://doi.org/10.1016/j. clinbiochem.2016.05.022

24. Grainger DJ, Heathcote K, Chiano M, Snieder H, Kemp PR, Metcalfe JC, Carter ND, Spector TD (1999) Genetic control of the circulating concentration of transforming growth factor type beta1. Hum Mol Genet 8(1):93-97. https://doi.org/10.1093/hmg/8.1.93

25. Cao H, Zhou Q, Lan R, Røe OD, Chen X, Chen Y, Wang D (2014) A Functional polymorphism C-509T in TGF $\beta-1$ promoter contributes to susceptibility and prognosis of lone atrial fibrillation in Chinese population. PLoS One 9(11):e112912. https://doi.org/10.1371/journal.pone.0112912

26. Gunes Y, Boztosun B, Yildiz A, Metin Esen A, Saglam M, Bulut M, Karapinar $\mathrm{H}$, Kirma C (2006) Clinical profile and outcome of coronary artery ectasia. Heart 92(8):1159-1160. https://doi.org/10.1136/hrt.2005.069633

27. Kamal D, Hashem M (2020) Role of QRS fragmentation in 12-lead surface ECG in prediction of isolated epicardial coronary artery ectasia and its anatomical distribution in patients without acute coronary syndromes. Egypt Heart J 72(1):20. https://doi.org/10.1186/s43044-020-00054-4

\section{Publisher's Note}

Springer Nature remains neutral with regard to jurisdictional claims in published maps and institutional affiliations.

\section{Submit your manuscript to a SpringerOpen ${ }^{\circ}$ journal and benefit from:}

- Convenient online submission

- Rigorous peer review

- Open access: articles freely available online

High visibility within the field

- Retaining the copyright to your article

Submit your next manuscript at $>$ springeropen.com 